\title{
É o Sistema Único de Saúde-SUS para os pobres?
}

Is the Unified Health System-UHS for the poor people?

És lo Sistema Único de Salud-SUS para el pueblo pobre?

Oswaldo José Barbosa Silva ${ }^{1}$

RESUMO: objetivo: Discutir os princípios que norteiam o SUS, especialmente o da universalidade e o da igualdade que evoluíram em um processo histórico no curso do qual, apropriados pela reforma sanitária brasileira, foram positivados na Constituição Federal e nas leis que os regulamentam. Contudo, contrariamente a esses princípios, subsiste em todas as instâncias da federação brasileira, uma clientela exclusiva beneficiária de ações e serviços públicos de saúde ou, ainda de verbas públicas aplicadas em sua aquisição: os servidores públicos. Metodologia: mediante uma revisão de literatura, do arcabouço legal, da hermenêutica constitucional e de levantamento de dados orçamentários, verifica-se que os resultados revelam a inconstitucionalidade das leis orçamentárias que autorizam prover essas ações e serviços. Resultados: a discussão do tema autoriza a dizer que, politicamente e juridicamente, é muito difícil reverter tal situação em prol da credibilidade do SUS o que leva à conclusão, título do presente trabalho.

Palavras-chave: Sistema Único de Saúde. Direito à Saúde. Universalidade. Igualdade.

ABSTRACT: objective: Discuss about the Brazilian Unified Health System (SUS) systematic, the principles of universality and equality came from a historical process, included in Brazilian Federal Constitution when recognized in the legal sanitary reform. However, in contrary to these principles, there is an exclusive clientele in public health actions, in all instances of the Brazilian federation: public servants are being benefited with exclusive public funds on their own health care. Methods: This paper makes a review of the literature, of the law, of the jurisprudence and of empirical data, to shows that the budged laws are unconstitutional when authorize to finance specific health care to public servants. Results: This discussion authorizes to say, in the political and legal instances, it is very difficult to reverse this situation in favor of SUS's credibility, which leads to the conclusion in the title of the present work.

Keywords: Brazilian Unified Health System. Public Healh Care. Right to Health, Universality. Equality

RESUMEN: objective: discutir los principios que orientan el SUS, especialmente sobre la universalidad y la igualdad que evolucionaron en un proceso histórico en el curso del cual, apropiados por la reforma sanitaria brasileña, fueron estipulados en la Constitución Federal y en las leyes que los reglamentan. Pero, contrariamente a esos principios subsiste en todas las instancias de la federación brasileña, una clientela exclusiva beneficiaria de

\footnotetext{
1 Mestrando em Políticas Públicas em Saúde pela Fiocruz-Brasília, Subprocurador-Geral da República, Procuradoria Geral da República, Ministério Público Federal, Brasília, Distrito Federal, Brasil. E-mail: oswaldo@mpf.mp.br
} 
acciones y servicios públicos de salud o, aún de presupuestos públicos aplicadas en su adquisición: los funcionarios públicos. Metodología: mediante una revisión de literatura, del acervo legal, de la hermenéutica constitucional y de recopilación de datos presupuestarios, se verifica que los resultados revelan la inconstitucionalidad de las leyes presupuestarias que autorizan proveer esas acciones y servicios. Results: La discusión del tema autoriza a decir que política y jurídicamente es muy difícil revertir tal situación en pro de la credibilidad del SUS lo que lleva a la conclusión, título del presente trabajo.

Palabras Ilave: Sistema Único de Salud. Derecho a la Salud. Universalidad. Igualdad.

\section{Introdução}

A saúde é uma necessidade de sobrevivência da pessoa e até que contemporaneamente fosse reconhecida como um direito público subjetivo (direito social), contra o estado, veio historicamente caminhando no sentido desse reconhecimento de mãos dadas com a previdência social e a assistência social, passando por quatro fases distintas (1).

A primeira fase caracterizou-se pela ausência da proteção social do estado, a sociedade cuidava de sua própria proteção, por meio de corporações profissionais, mutualistas e da caridade, religiosa ou não. A segunda fase se deu a partir da Lei dos Pobres (1601), onde verificou-se, na Inglaterra, a primeira intervenção protetiva do estado, por meio da garantia de auxílio aos necessitados. A terceira fase deu-se na Alemanha por iniciativa de Otto Von Bismarck que, no período de 1881 a 1889, implantou um sistema de segurança social de natureza previdenciária provido pelos trabalhadores, empregadores e pelo estado. Por fim, a quarta fase encontra seu marco inicial em 1941, também na Inglaterra onde, em face da segunda guerra mundial, criou-se uma comissão para recomendar mudanças no regime de proteção social então vigente. A comissão, presidida por William H. Beveridge, produziu um documento intitulado: "Seguro Social e Serviços Afins. Informe de Lorde Beveridge" (Report on Social Insurance and Allied Services).

Esse relatório é o marco inicial do moderno welfare state britânico e nele sugere-se a prestação de serviços de saúde, pelo governo, com qualidade e gratuidade. Em 1946 a reforma da saúde na Inglaterra instituiu, observando o relatório, o National Health Service (NHS) o qual serviu de referência para o movimento da reforma sanitária brasileira construir o conhecimento acadêmico que serviu de referencial teórico para a proposta do Sistema Único de Saúde, defendida na 8a․ Conferência Nacional de Saúde (1986) e 
inscrita como opção política de organização da seguridade social, dentro do título da ordem social na Constituição Federal de 1988. (2)

Após declarar que a saúde é um direito de todos e um dever do estado e garantir o acesso universal e igualitário (art. 196), a CF/88 estabelece que as ações e serviços públicos de saúde integram uma rede regionalizada e hierarquizada e constituem um sistema único organizado e de acordo com as diretrizes que enumera (art. 198).

Constata-se, na CF/88, que o sistema único tem, como princípio básico, o acesso universal e igualitário à saúde por todas as pessoas que se encontram no território nacional. Esses dois princípios são repetidos na Lei Orgânica da Saúde (Lei 8.080/1990), nos incisos I e IV do art. $7^{\circ}$. (3)

O princípio da gratuidade, que embora não explícito na Constituição, está implícito em outros dois princípios ali declarados, os princípios da universalidade e da igualdade (4), pois "seria um contrassenso falar em acesso universal e igualitário e exigir-se uma contribuição social específica ou remuneração de determinado serviço pelo cidadão"2. Esse princípio veio a ser expresso pela Lei Complementar no 141, de 2012 (5), que somente admite a aplicação (despesa) de verbas públicas em saúde em ações e serviços de acesso universal, igualitário e gratuito (art. $2^{\circ}$, I).

Vê-se, entretanto, ainda hoje, no serviço público dos três poderes da União, Estados, Distrito Federal e dos Municípios que os servidores públicos usufruem, com exclusividade, de serviços de assistência médica e odontológica, provida total ou parcialmente com recursos públicos; no primeiro caso com ambulatórios e clínicas, administradas pela própria unidade administrativa; no segundo caso com planos de saúde que contratam serviços privados mediante um fundo provido pelo estado e pelos servidores usuários.

Essa assistência médica e odontológica, direta ou indireta, encontra sustentação legal na Lei 8.112 de 1990 (art. 230) (6) e nas autorizações orçamentárias das anuais leis de diretrizes orçamentárias e leis orçamentárias dos entes federados; no entanto, por outro lado, a Lei Complementar nº 141 de 2012 não reconhece como ações ou serviços públicos de saúde aqueles de assistência à saúde que não atendam ao princípio do acesso universal e igualitário (arts $2^{\circ}$, I e $4^{\circ}$, III).

\footnotetext{
${ }^{2}$ Apud (Carvalho e Santos, 1995).
} 
O propósito deste artigo é examinar em que medida dois princípios norteadores do Sistema Único de Saúde-SUS (universalidade e gratuidade) são solapados pela legislação infraconstitucional, que vem permitir que ações e serviços públicos de saúde possam ser destinados a clientela exclusiva ou, ainda, que verbas destinadas à sua aplicação podem ser a essa clientela exclusiva destinada, de forma a complementar aquisição de serviços privados de saúde.

Para proceder a esse exame, impõe-se trazer a lume a compreensão de como o princípio da universalidade e da igualdade se expressam na constituição e na lei; como se apresenta, na doutrina, os conceitos sobre a universalidade e igualdade no sistema, bem assim como a jurisprudência constitucional se manifesta; e, por fim, trazer exemplos de como se realiza, no plano orçamentário e da execução financeira, a destinação de verbas públicas para a saúde a contemplar clientela específica, separada da universalidade dos demais usuários do SUS.

Ao final, propõe-se interpretar e discutir a situação examinada à luz da Constituição e apontar as implicações que esse modelo, hoje existente, pode suscitar.

\section{Metodologia}

Fez-se uma revisão de literatura, onde se encontrará o arcabouço legal no qual se estatui a universalidade na prestação dos serviços de saúde, bem assim o pensamento dos autores na doutrina dos conceitos sobre esse princípio. Foi também contemplado o exame da jurisprudência dos tribunais superiores e o levantamento, exemplificativo, dos dados orçamentários de órgãos federais dos três poderes da União e do próprio Ministério Público da União, dispostos para livre acesso nos respectivos sítios da internet. Tratou-se, portanto, de um estudo analítico-descritivo de base documental.

\section{Resultados e discussão}

A CF/88 já em seu preâmbulo afirma instituir um estado democrático de direito destinado a assegurar, entre outros valores, a igualdade como um valor supremo de uma sociedade fraterna, pluralista e sem preconceitos. Para tanto estabeleceu, em um título, rol de direitos e garantias fundamentais que, em um capítulo, tratou dos direitos e deveres individuais e coletivos, tendo como primeira prescrição de que todos são iguais perante a 
lei (art. $\left.5^{\circ}\right)$; em outro, tratou dos direitos coletivos, instituindo a saúde como um direito social (art. 6ำ). (2)

A saúde teve um tratamento específico na Constituição. Integrou o título da Ordem Social (título VIII) cuja base é o primado do trabalho e como objetivo o bem-estar e a justiça sociais (art. 193) (2). Sua integração se deu no capítulo (II do título VIII) da Seguridade Social, juntamente com a previdência social e a assistência social. A Seguridade Social, segundo a Constituição, tem objetivos comuns aos seus três ramos, previstos no parágrafo único do art. 194, dos quais, para o que interessa ao presente trabalho, são: a universalidade da cobertura e do atendimento; a uniformidade e equivalência dos benefícios e serviços às populações urbanas e rurais; e a seletividade e distributividade na prestação dos benefícios e serviços.

A seção em que a saúde encontra seu tratamento constitucional inicia no art. 196, verbis:

Art. 196. A saúde é direito de todos e dever do Estado, garantido mediante políticas sociais e econômicas que visem à redução do risco de doença e de outros agravos e ao acesso universal e igualitário às ações e serviços para sua promoção, proteção e recuperação. (2)

Até esse ponto da leitura constitucional procurou-se relevar a cobertura (acesso) universal e igualitário de todos os usuários de saúde, como expressão de justiça social. Continuando nesta leitura, vê-se que a prestação das ações e serviços públicos de saúde, pelo estado, em face do direito público subjetivo outorgado a todas as pessoas no território nacional, pela CF/88, constituem um sistema único, mediante uma rede regionalizada e hierarquizada (art. 198).

A Lei Orgânica da Saúde (Lei № 8.080 de 1990) (3) é a que primeiro regulamentou os artigos constitucionais sobre a saúde e, no que tange ao tema acima posto em relevo, na leitura constitucional estatuiu o dever do estado em assegurar acesso universal e igualitário às ações e aos serviços para sua promoção, proteção e recuperação (art. $2^{\circ}$, $\S$ $\left.1^{\circ}\right)$. Adiante declara que as ações e serviços públicos de saúde e os serviços privados contratados ou conveniados integram o Sistema Único de Saúde (SUS) e que serão desenvolvidas, dentre outros, pelos seguintes princípios: universalidade de acesso aos serviços de saúde em todos os níveis de assistência; e igualdade de assistência à saúde, sem preconceitos ou privilégios de qualquer espécie (art. 7ํㅜ I e IV). 
Mais recentemente veio a Lei Complementar nํ 141, de 2012 (5), a regular, também, a CF/88, mas tratando do financiamento da saúde, de modo a atender ao comando constitucional previsto no $\S 3^{\circ}$, do art. 198. Essa regulação veio a reforçar mais ainda o princípio da cobertura universal e igualitária, não considerando como ação ou serviço público de saúde, portanto insuscetível de financiamento público, aquela que não fosse destinada mediante acesso universal igualitário e gratuito (art. $2^{\circ}, \S 1^{\circ}$ ), ao passo que para reforçar essa prescrição, declara adiante (art. $4^{\circ}$, III) que não se constituirão despesas com ações e serviços públicos de saúde aquelas decorrentes de assistência à saúde que não atenda ao princípio de acesso universal.

No sentido contrário aos preceitos da CF/88 e da Lei Complementar № 141 de 2012 temos leis hierarquicamente inferiores que possibilitam a aplicação de verbas públicas para a assistência médica e odontológica (serviços de saúde) para clientela exclusiva, os servidores públicos federais. A Lei no 8.112 de 1990 (Regime Jurídico dos Servidores Públicos Civis da União) ${ }^{3}$ prescreve, em seu art. 230, verbis:

Art. 230. A assistência à saúde do servidor, ativo ou inativo, e de sua família compreende assistência médica, hospitalar, odontológica, psicológica e farmacêutica, terá como diretriz básica o implemento de ações preventivas voltadas para a promoção da saúde e será prestada pelo Sistema Único de Saúde - SUS, diretamente pelo órgão ou entidade ao qual estiver vinculado o servidor, ou mediante convênio ou contrato, ou ainda na forma de auxílio, mediante ressarcimento parcial do valor despendido pelo servidor, ativo ou inativo, e seus dependentes ou pensionistas com planos ou seguros privados de assistência à saúde, na forma estabelecida em regulamento. (6)

Está clara a exceção ao princípio da cobertura universal e igualitária do SUS, seja porque os servidores públicos civis federais, ou militares, receberão assistência médica e odontológica nas próprias unidades em que trabalham (por meio de ambulatórios, clínicas e hospitais próprios), seja por meio de pagamento, com verbas públicas, de um auxílio constituído pelo ressarcimento (mesmo que parcial) do valor dispendido pelo servidor com planos ou seguros privados de assistência à saúde.

Para tanto, as leis de diretrizes orçamentárias e as leis orçamentárias anuais da União Federal autorizam esse tipo de despesa. Apenas para exemplificar, no exame da Lei

\footnotetext{
${ }^{3}$ Os servidores públicos militares contam com estatuto próprio que lhes confere o mesmo direito (Lei 6.880 de 1980 ,
} artigo 50, e) 
13.408 de 26 de dezembro de 2016 (7) (Lei de Diretrizes Orçamentárias), verifica-se, no artigo $111^{4}$, a autorização legal para a despesa com serviços médicos e odontológicos para os servidores.

À conta do orçamento da seguridade social, a autorização orçamentária provê o atendimento dessa clientela exclusiva, especificamente para que os órgãos possam contribuir parcialmente para o pagamento de planos de saúde privados. Por exemplo, vêse na tabela 1 que para o exercício de 2017, tem-se previsão, na LOA, dos valores abaixo apontados, para os órgãos de cúpula dos poderes da União, do Ministério Público e da Defensoria.

Tabela 1 - Extrato do Volume 1, Do Orçamento Fiscal e da Seguridade Social (8)

\begin{tabular}{|l|l|}
\hline \multicolumn{2}{|c|}{$\begin{array}{l}\text { Quadro } 12 \text { Ações da Seguridade Social, respectivos Programas e Órgão Orçamentário LDO- } \\
\text { 2017o I, inciso XII 347 - R\$ 1,00 Recursos de todas as fontes }\end{array}$} \\
$\begin{array}{l}\text { 2004 - Assistência Médica e Odontológica aos Servidores Civis, Empregados, Militares e seus } \\
\text { Dependentes }\end{array}$ & $\mathrm{R} \$ 118.362 .216$ \\
\hline Senado Federal & $\mathrm{R} \$ 108.747 .756$ \\
\hline Câmara dos Deputados & $\mathrm{R} \$ 43.641 .264$ \\
\hline Presidência da República ${ }^{5}$ & $\mathrm{R} \$ 14.920 .584$ \\
\hline Supremo Tribunal Federal ${ }^{6}$ & $\mathrm{R} \$ 129.987 .942$ \\
\hline Ministério Público da União ${ }^{7}$ & $\mathrm{R} \$ 4.825 .596$ \\
\hline Defensoria Pública da União & \\
\hline
\end{tabular}

Fonte: Orçamento Anual de 2017 - Ministério do Planejamento, Desenvolvimento e Gestão

O total desse dispêndio para a União, no ano de 2017, para todos os seus órgãos da administração direta (incluídos militares e excluídas autarquias e empresas públicas), acrescidos da Polícia Militar, Corpo de Bombeiros Militar e Polícia Civil do Distrito Federal (providos por fundo constitucional) somou $\mathrm{R} \$ 6.321 .422 .719,00 .^{8}$ Neste valor não estão

\footnotetext{
${ }^{4}$ Art. 111 . O limite relativo à proposta orçamentária de 2017, para os Poderes, o Ministério Público da União e a Defensoria Pública da União, concernentes ao auxílio-alimentação ou refeição, à assistência pré-escolar, à assistência médica e odontológica, nesta incluídos os exames periódicos, e ao auxílio-transporte, corresponderá à projeção anual, calculada a partir da despesa vigente em março de 2016, compatibilizada com as despesas apresentadas até esse mês, com os totais de beneficiários e valores per capita divulgados nos sítios na internet, nos termos do art. 112 e os eventuais acréscimos legais, observado o disposto no $\S 20$ do art. 114.

${ }^{5}$ Apenas esse órgão, e não seus subordinados da administração direta e indireta.

${ }^{6}$ Apenas o órgão de cúpula do Poder Judiciário, não inclui os tribunais superiores, os federais regionais e regionais do trabalho e os juízes federais e do trabalho.

7 MPF, MPT, MPM e MPDFT

${ }^{8}$ Fonte: Orçamento Anual de 2017 - Ministério do Planejamento, Desenvolvimento e Gestão.
} 
incluídas as despesas com ambulatórios ou clínicas próprias, eventualmente existentes em cada órgão público ${ }^{9}$, pois estas despesas são previstas no orçamento fiscal da União, como custeio de pessoal.

No plano da hermenêutica constitucional, pesquisa na jurisprudência do Supremo Tribunal Federal (9) revela que o art. 230 da Lei 8.112 de 1990, não foi ainda objeto de exame de sua constitucionalidade por aquela corte. O tema foi tangenciado pela propositura da ADIn 5.086, ajuizada pelo Conselho Federal da Ordem dos Advogados do Brasil, que se insurgiu contra o Decreto $(s / n)$ de 7 de outubro de 2013, que visava concentrar na GEAP - Autogestão em Saúde, todos os contratos e convênios de assistência médica patrocinados pela União para seus servidores ou empregados ativos, aposentados e pensionistas e seus dependentes. Nesse processo discutiu-se apenas se a União poderia eleger uma patrocinadora de serviços de assistência médica, a GEAP, sem licitação, em detrimento de todas os outros planos de saúde privados. A liminar foi concedida em janeiro de 2014 e o processo aguarda julgamento de mérito. Percebe-se que, sequer incidentalmente, foi suscitada a questão da possibilidade da União usar verbas federais destinadas à saúde para clientela exclusiva.

Por outro lado, no que tange às leis de diretrizes orçamentárias e leis orçamentárias da União, o fato de se submeterem ao regime da anualidade praticamente impede o exame de sua constitucionalidade vez que, em face da notória morosidade do Poder Judiciário, antes do julgamento do mérito de uma ação com esse propósito, as leis perdem sua vigência (anual), restando sem objeto a correspondente ação, pelo que são arquivadas.

Na doutrina, Menicucci (10) foi cirúrgica em perguntar qual era a sustentação política e legitimidade dos princípios definidos para o SUS que permitisse a efetiva universalidade e igualdade. Mesmo no quadro atual, em 2017, a resposta por ela encontrada há quase dez anos permanece atual: a fragilidade da base de apoio política para a implantação da reforma sanitária, materializada no SUS, engendrou a formulação de políticas públicas, cujo resultado foi a consolidação de um sistema híbrido, público e privado, apesar da base de legitimação constitucional legal que impõe um sistema único, universal e gratuito.

\footnotetext{
${ }^{9}$ É notório que em diversos órgãos dos três poderes da União existem ambulatórios médicos e clínicas odontológicas montadas, na própria sede do órgão, para atenderem membros e servidores.
} 
Bahia (11) denuncia, por sua vez, que o aparato jurídico-legal, parte do qual foi acima apresentado, "mascara a vigência de uma política pública de inclusão seletiva de demandas" a evidenciar as "contradições entre o circuito econômico-político no qual se inscrevem as empresas de planos e seguros de saúde e a universalidade do sistema de saúde brasileiro".

Vale a pena transcrever, tanto quanto fez Santos (12), o ensinamento de Alessandra Silveira (13), acerca do art. 198, da Constituição Federal:

É vedado a qualquer ente político-administrativo constituir um plano ou programa de saúde à parte do SUS, posto que a Constituição cria um sistema de serviço unificado e fundado na obrigatória conjugação de esforços.

Os princípios de justiça social, universalidade e igualdade previstos nos princípios fundamentais, na ordem social, na seguridade social e na saúde, tal como se encontram na CF/88 e na Lei Orgânica da Saúde, bem assim as prescrições da Lei Complementar 141 de 2012 a reger a forma de dispêndio das verbas aplicadas à saúde, contrastam com a realidade de desigualdade no acesso à saúde entre segmentos da população brasileira.

À população em geral é prometido um acesso universal, igualitário e gratuito por meio de um sistema único, para o qual as verbas públicas da saúde devem ser exclusivamente destinadas. A promessa não se cumpre quando se aplica parte dessa verba, tanto do orçamento fiscal da União, quanto do orçamento da seguridade, à clientela exclusiva (servidores públicos civis ${ }^{10}$ e militares), seja pelo patrocínio de planos de saúde de natureza privada, seja pela oferta direta de serviços médicos e odontológicos. Registre-se que tal conduta se verifica nos outros entes federados, estados, distrito federal e municípios.

É então o próprio Estado que dá significado à expressão de que o SUS é para os pobres. Seus servidores não utilizam o SUS ${ }^{11}$, optando pelo pagamento de planos de saúde patrocinados, em parte, com verbas públicas que deveriam ser destinadas, dentro da unicidade do sistema, ao SUS.

\footnotetext{
10 Inclusive os do Ministério da Saúde suas autarquias e fundações e o autor deste artigo, membro do MPF.

11 Exceto talvez, para procedimentos e medicamentos de alto custo.
} 
A classe média e alta brasileira não utiliza o $S_{U} S^{12}$ e isso, no entendimento Paim e Silva (14), pode atrasar, ainda mais, o objetivo de igualdade (equidade) no SUS:

O sistema de saúde, ao ser universal, pressiona em termos de qualidade, tendo em vista a sua utilização por todas as classes sociais, ou pelo menos por parte das classes médias dotadas de maior poder de barganha e interferência no campo político. Dessa forma, conceber e implementar serviços de saúde universais pode ser uma estratégia de assegurar às classes populares acesso a serviços de melhor qualidade e, portanto, exercitar a equidade.

Mas se o estado não confia em seu próprio sistema, não pode ele esperar que as classes "dotadas de maior poder de barganha e interferência no campo político" possam dele se valer, de modo a que se pudesse nele experimentar um ganho de qualidade.

Outros fatos graves exsurgem pela simples leitura dos normativos constitucionais e legais. Ao assim agir o estado demite-se, pelo menos em relação ao segmento que beneficia, de seu dever de gerir a saúde mediante uma rede hierarquizada e regionalizada com direção única, em cada esfera de governo (CF/88, art. 198); transfere verbas públicas destinadas à saúde a setores que não tem responsabilidade específica do setor de saúde (LC 141, art. $2^{\circ}$, III); e propicia duplicidade na organização dos serviços públicos para fins idênticos (Lei 8.080 de 1990, art. 7º, XIII).

Rigorosamente, o confronto entre o que prescreve a CF/88 e a Lei Complementar no 141 de 2012 vis-à-vis com o art. 230 da Lei 8.112/90 e a anuais Leis de Diretrizes Orçamentarias e Leis do Orçamento Anual, desafia a propositura de ação direta de inconstitucionalidade perante o Supremo Tribunal Federal, para afastar, como inconstitucional, os artigos que, nessas leis, autorizam os gastos dessa natureza. Contudo, o histórico quadro de fragilidade da base de apoio política para apoiar esses princípios de justiça social, consagrados na 8ª Conferência Nacional de Saúde, somado ao fato, de crucial importância, de que todos os envolvidos nesse desafio jurídico são beneficiários e usuários de planos de saúde patrocinados pelo Estado, indica que uma iniciativa dessa natureza certamente não terá sucesso. A situação como está compromete substancialmente a credibilidade do Sistema Único de Saúde como um instrumento de

\footnotetext{
12 Idem.
} 
justiça social, universal, igualitário e gratuito no oferecimento à população em geral de ações e serviços públicos de saúde.

Essa ausência de credibilidade, à parte os problemas de implantação do próprio SUS, é um estímulo à população com alguma renda a valer-se da saúde complementar (planos de saúde) para receber serviços de saúde. Essa situação remete-nos à pergunta que intitulo o presente artigo.

\section{Conclusão}

A resposta que o estado dá é que o SUS é para os pobres. E, sendo para os pobres, ainda tem que suportar as demandas de alta complexidade ou de componentes da assistência farmacêutica especializada por parte daqueles que já recebem do estado, como clientela exclusiva, recursos para ações e serviços públicos de saúde. O que se dá em decorrência da má vontade dos planos de saúde em investir em alta complexidade ou de custear medicamentos.

Por não ser igualitário, o SUS sofre de um déficit de pressão por qualidade, por parte de significativos segmentos que, embora sujeitos à sua cobertura universal, não se interessam por sua total implementação, por serem subsidiados e estimulados a comprarem ações e serviços de saúde no mercado.

\section{Referências}

1.Pierdoná ZL. A proteção social na Constituição de 1988. Revista de Direito Social, Notadez, Porto Alegre. 2007.

2. Brasil. Constituição da República Federativa do Brasil. 5 de outubro de 1988. Brasília. Disponível em:> http://www.planalto.gov.br/ccivil 03/constituicao/constituicao.htm [Acesso em 19.jun.2017].

3. Brasil. Lei no 8.080, de 19 de setembro de 1990. Dispõe sobre as condições para a promoção, proteção e recuperação da saúde, a organização e o funcionamento dos serviços correspondentes e dá outras providências. Brasília. 20 set 1990. Disponível em http://www.planalto.gov.br/ccivil 03/leis/L8080.htm [acesso em 19.jun.2017]. 
4. Vianna SM, Piola SF, Ocké Reis CO. Gratuidade no SUS: controvérsia em torno do copagamento. IPEA. Brasília. 1998:18.

5. Brasil. Lei Complementar no 141, de 13 de janeiro de 2012. Regulamenta o § 3ㅇ do art. 198 da Constituição Federal para dispor sobre os valores mínimos a serem aplicados anualmente pela União, Estados, Distrito Federal e Municípios em ações e serviços públicos de saúde; estabelece os critérios de rateio dos recursos de transferências para a saúde e as normas de fiscalização, avaliação e controle das despesas com saúde nas 3 (três) esferas de governo. Brasília. 16 jan 2012. Disponível em http://www.planalto.gov.br/ccivil 03/leis/LCP/Lcp141.htm [Acesso em 19.jun.2017].

6. Brasil. Lei 8.112, de 11 de dezembro de 1990. Dispõe sobre o regime jurídico dos servidores públicos civis da União, das autarquias e das fundações públicas federais. Brasília. 19 abr 1991. Disponível em http://www.planalto.gov.br/ccivil 03/leis/L8112compilado.htm [Acesso em 19.jun.2017].

7. Brasil. Lei no 13.408, de 26 de dezembro de 2016. Dispõe sobre as diretrizes para a elaboração e execução da Lei Orçamentária de 2017 e dá outras providências. Brasilia. 27 dez 2017. Disponível em http://www.planalto.gov.br/ccivil 03/ ato20152018/2016/lei/L13408.htm [Acesso em 19.jun.2017].

8. Brasil. Lei 13.414, de 10 de janeiro de 2017. Estima a receita e fixa a despesa da União para o exercício financeiro de 2017.Brasília. 11 jan 2017. Disponível em http://www.planalto.gov.br/ccivil 03/ ato2015-2018/2017/lei/L13414.htm [Acesso em 19.jun.2017].

9. Supremo Tribunal Federal, Adin 5.086. Autor: Conselho Federal da Ordem dos Advogados do Brasil. Relator: Min. Luiz Fux. Brasília, 24 jan 2014. Liminar 10 fev 2014, deferindo em parte. Brasília. DJE 27: 10 fev 2014.

10. Menicucci TM. O Sistema Único de Saúde, 20 anos: balanço e perspectivas The Unified National Health System, 20 years: assessment and perspectives. Cad. Saúde.Pública. 2009 Jul;25(7):1620-5.

11. Bahia L. As contradições entre o SUS universal e as transferências de recursos públicos para os planos e seguros privados de saúde. Ciência \& saúde coletiva. 2008;13(5).

12. Santos L. SUS e a Lei Complementar 141 comentada. InSUS e a lei complementar 141 comentada 2012. Campinas: Saberes. 2012. p. 19.

13. Silveira, A. Cooperação e Compromisso Constitucional nos Estados Compostos. Estudo sobre a Teoria do Federalismo e a Organização Jurídica dos Sistemas Federativos. Coimbra, Portugal: Almedina, 2007, p. 136.

14. Paim J, Silva L. Universalidade, integralidade, equidade e SUS. BIS, Bol. Inst. Saúde (Impr.) [periódico na Internet]. 2010 Ago [citado 2017 Jun 13] ; 12(2): 109-114. 
Cadernos Ibero-Americanos

de Direito Sanitário

Cuadernos Iberomericanos

de Derecho Sanitario

Disponível em: http://periodicos.ses.sp.bvs.br/scielo.php?script=sci arttext\&pid=S1518$18122010000200002 \&$ lng $=$ pt. [Acesso em 19.jun.2017]

Recebido em: 20.6.2017

Aprovado em: 22.6.2017

Como citar este artigo:

Silva OJB. É o Sistema Único de Saúde-SUS para os pobres?. Revista Cadernos Ibero-Americanos de Direito Sanitário. 2017 abr./jun, 6(2):180-192. 